\title{
MEMPERKENALKAN DUNIA BINATANG MELALUI PENYUTRADARAAN PROGRAM MAGAZINE SHOW “FUNTASY ZOO" E PISODE KUCING DENGAN PENGGUNAAN GAYA VISUAL FLAT DESIGN
}

\author{
Bunga Nindiah Septiani \\ Agnes Widyasmoro \\ Andri Nur Patrio \\ Jurusan Film \& Televisi, Fakultas Seni Media Rekam, Institut Seni Indonesia Yogyakarta \\ Jl. Parangtritis km. 6.5 Yogyakarta Telp. (0274) 381047
}

\begin{abstract}
ABSTRAK
Anak dan remaja sering kali menjadikan binatang peliharaan sebagai salah satu life style trending item dengan pembekalan pengetahuan yang minim. Kurangnya pengetahuan tentang merawat binatang peliharaan menjadikan binatang peliharaan tersiksa dan menyebabkan manusia menjadi bingung dengan tindakan perawatannya. Program peliputan aktivitas binatang maupun pengetahuan dasar binatang telah ditayangkan di televisi Indonesia dalam bentuk feature maupun dokumenter. Hal inilah yang menjadi latar belakang dalam penciptaan program magazine show bertema binatang.

Program magazine show "Funtasy Zoo" adalah program yang membahas seputar binatang dengan tema yang menyenangkan dan memainkan fantasi dalam penyajiannya. Pada season 1 bertema binatang peliharaan yaitu kucing. Melalui skripsi penciptaan seni berjudul "Memperkenalkan Dunia Binatang Melalui Penyutradaraan Program Magazine Show "Funtasy Zoo" Episode Kucing Dengan Penggunaan Gaya Visual Flat Design" bertujuan untuk mengenalkan dunia binatang khususnya kucing lebih mendalam dengan bahasa yang ringan dan tampilan yang menarik menggunakan gaya flat design untuk mendukung visual agar menarik minat penonton terutama anak dan remaja.

Program "F untasy Z00" berisi 7 rubrik, berdurasi 30 menit dengan pembawaan yang menarik, menyenangkan dan didukung oleh penyajian gaya flat design seperti menggunakan warna cerah dan ilustrasi. Dengan adanya program ini, diharapkan mampu menambah wawasan kepada masyarakat mengenai binatang, baik dari karakter sampai cara merawatnya dan menambah referensi dan hiburan kepada masyarakat terkait binatang.
\end{abstract}

Kata Kunci : Binatang, Flat Design, Magazine Show

\section{Pendahuluan}

Anak dan remaja sering kali menjadikan binatang peliharaan sebagai salah satu life style trending item. Sebagai contoh, jika pada suatu masa sedang trend binatang Sugar Glider, maka banyak masyarakat yang memelihara binatang tersebut, namun banyak yang kurang paham bagaimana cara merawat binatang tersebut. Binatang peliharaan juga dijadikan alasan adanya komunitas untuk menjalin silaturahmi antar pemilik binatang peliharaan. Kurangnya pengetahuan tentang merawat binatang peliharaan menjadikan binatang peliharaan tersiksa dan menyebabkan manusia menjadi bingung dengan tindakan perawatannya. Binatang yang dirawat hanya sekedar diberi makan, padahal membutuhkan pengetahuan khusus untuk merawat binatang, seperti cara memandikan dan perawatan khusus lainnya 
karena berbeda binatang, berbeda pula karakteristiknya.

Program peliputan aktivitas binatang maupun pengetahuan dasar binatang telah ditayangkan di televisi Indonesia dalam bentuk feature maupun dokumenter. Masyarakat juga membutuhkan berita serta hiburan tentang dunia binatang karena binatang adalah makhluk yang sudah melekat dalam kehidupan manusia. Hal inilah yang menjadi latar belakang dalam penciptaan program magazine show bertema binatang.

Program acara bernama "Funtasy Zoo", singkatan dari fun, fantasy, dan zoo yang berarti kebun binatang khayalan yang menyenangkan dalam bahasa Indonesia. Sebagai perwujudan khayalan penulis berupa bagaimana bila ada suatu program pengetahuan binatang dengan pembawa acara yang memakai kostum dan riasan terinspirasi oleh binatang yang sedang dibawakan pada tayangan tersebut. Nama tersebut dipilih karena mewakili tema acara yang merupakan tema binatang dengan pembawa acara yang ceria, menyenangkan dan penuh dengan fantasi karena pembawa acara akan memakai kostum dan riasan sesuai dengan topik pembahasan binatang yang ditayangkan.

\section{Program "Funtasy Zoo" adalah} program magazine show yang membahas seputar binatang dengan tema yang menyenangkan dan memainkan fantasi dalam penyajiannya, sehingga diharapkan dapat memberikan pengetahuan tentang binatang namun tetap menghibur. Informasi tersebut akan dikemas ke dalam 7 rubrik yang terbagi dalam 3 segmen. Program ini akan dipandu oleh satu orang pembawa acara remaja wanita yang akan memakai kostum kucing. Program "Funtasy Zoo" menggunakan flat design sebagai pendukung visual dengan penggunaan pola binatang dan warna-warna cerah sehingga cocok untuk mendukung program magazine show binatang bertarget audiens anak hingga remaja yang enerjik dan ceria. Penggunaan tipografi juga diterapkan sebagai pendukung informasi visual yaitu dengan pemilihan fontfont yang sesuai dengan konsep program "F untasy Zoo" yang bertema kebun binatang khayalan yang menyenangkan.

Program "Funtasy Zoo" memilih kucing karena kucing adalah salah satu hewan yang banyak dijumpai dan dipelihara oleh manusia. Informasi tentang kucing, fakta menarik, serta pengetahuan tentang kucing, akan berguna bagi masyarakat khususnya pecinta kucing. Pembawa acara akan memakai kostum dan riasan yang terinspirasi dari kucing sehingga akan menarik perhatian penonton dan menjadi daya tarik serta mendukung tema program.

Program magazine show "Funtasy Zoo" berdurasi 30 menit yang terbagi menjadi 3 segmen. Program ini berisi 7 rubrik, yaitu perkenalan, berita, fakta menarik, tips kesehatan, lokasi unik, vox pop, 
dan video lucu yang berkaitan dengan kucing. Setiap rubriknya memiliki nama yaitu "Say, Hi!”, “Animazing!”, “Do You Know?", "Hello, Doctor!", "Hello, Hooman!", "Let's Play!" dan "Ganimalery" sebagai garis besar rubrik tersebut. Program yang berisi 7 rubrik ini akan terbagi menjadi 3 segmen dengan dibawakan oleh host remaja yang komunikatif, penggunaan bahasa yang ringan dengan gesture yang santai. Hadirnya program "Funtasy Zoo" diharapkan mampu menjadi program yang informatif, edukatif dengan tayangan yang disajikan dan inovatif karena program ini dikemas dengan format magazine show dan visual yang menarik dengan adanya host yang memakai kostum dan riasan binatang serta gaya visual flat design yang berwarna cerah. Tujuannya agar penonton tidak merasa jenuh serta tampilan menjadi lebih menarik dengan penggunaan warna-warna yang cerah, tipografi, dan ilustrasi sehingga sesuai dengan target penonton anak dan remaja.

Program "Funtasy Zoo" memiliki pengemasan gaya visual flat design dengan ciri-ciri yaitu warna-warna solid dan cerah, minimalis, tanpa dimensi (bayangan) ilustrasi, dan penggunaan tipografi yang mudah dibaca. Program "Funtasy Zoo" menggunakan warna-warna cerah seperti merah muda, merah, dan, oranye sebagai warna dominan pada visualnya. Tampilan grid dan split screen juga banyak dihadirkan untuk menandakan gaya visual flat design yang teratur dan rapi, penggunaan musik ceria serta editing sebagai media penggabungan unsur-unsur tambahan seperti penggunaan beberapa motion graphic.

\section{Konsep}

Konsep penyutradaraan program magazine "F untasy Zoo" menggunakan gaya visual flat design di setting virtual pada host dan grafisnya. Penggunaan grid pada beberapa frame, bumper, lower third, info grafis, split screen, dan credit tittle yang memiliki kesan menyenangkan dan ceria dengan dominan warna-warna cerah juga diterapkan dalam program ini. Terdapat 3 rubrik yang memiliki aspek informatif yaitu "Say, Hi!", "Animazing!", dan "Let's Play!", kemudian 3 rubrik dengan aspek edukatif yaitu "Do You Know?", "Hello, Doctor!" dan "Hello, Hooman!", serta 1 rubrik yang bersifat menghibur yaitu "Ganimalery".

Konsep pengambilan gambar dalam program "Funtasy Zoo" menggunakan dua kamera atau multicam dengan kamera mirrorless Sony A6000. Pengambilan gambar ini dilakukan di dalam studio greenscreen dan lokasi liputan. Pengambilan gambar untuk host dilakukan dengan menggunakan shot size Long Shot (LS) dan Medium Shot (MS) dengan sudut pengambilan straight-on angle, sedangkan untuk pengambilan gambar di lokasi liputan, akan menggunakan variasi shot size seperti Full Shot (FS), Medium Close Up (MCU), 


\section{Bunga Nindiah Septiani, Agnes Widyasmoro, Andri Nur Patrio}

Memperkenalkan Dunia Binatang Melalui Penyutradaraan Program Magazine Show "FU NTASY ZO0"

dan Close Up (CU) untuk menghindari

kejenuhan visual dan menambah aspek keindahan. Pada sesi wawancara, kamera akan memberikan ruang sisi kosong pada frame di sisi kanan atau kiri, tujuannya agar dapat dikelola editor untuk menambahkan info grafis sebagai penekanan informasi. Pergerakan kamera juga turut dihadirkan seperti panning dan tilt untuk menambah kedinamisan visual agar tidak monoton, mengingat program "Funtasy Zoo" adalah program magazine show.

Penataan suara menjadi aspek yang cukup penting dalam program magazine show. Pemaksimalan suara host di studio dan suara narasumber di lokasi liputan akan dilakukan dengan menggunakan mic clip on, sedangkan untuk suara pada pengambilan vox pop menggunakan mic dynamic. Musik jingle untuk bumper program "Funtasy Zoo" bertempo cepat dan bernuansa ceria sehingga lebih menarik minat penonton.

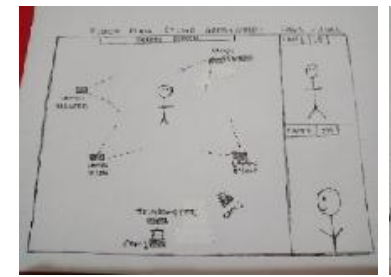

(i)

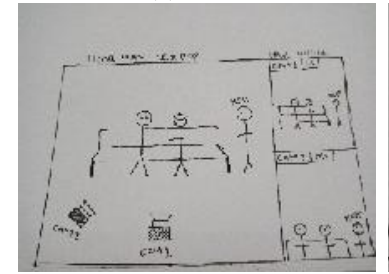

(iii)

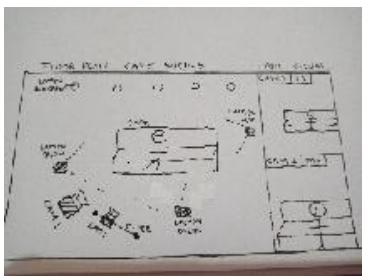

(ii)

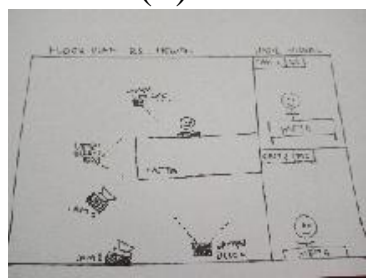

(iv)
Gambar 1. (i-iv). Konsep floorplan
Program

"Funtasy

Zoo"

menggunakan setting virtual dan tidak menggunakan properti dalam pengambilan gambar host. Hal ini dikarenakan pengambilan gambarnya dilakukan di studio greenscreen sehingga latar belakangnya akan diganti dengan desain kebun binatang sederhana yang merupakan ciri khas flat design. Pada pengambilan gambar di lokasi liputan, akan ditampilkan apa adanya, namun tetap memperhatikan kebersihan dan peletakan properti yang ada di lokasi dengan rapi dan minimalis, sehingga tetap memberikan kesan visual yang datar sesuai dengan gaya flat design.

Tata artistik juga mencakup kostum dan riasan. Kostum dan riasan yang digunakan adalah fantasi, karena mengingat tema program yaitu "Funtasy Zoo". Hal ini diwujudkan dengan kostum yang dipakai oleh host yaitu kostum yang terinspirasi oleh kucing. Host akan memakai atasan sabrina berwarna hitam, rok tutu pendek berwarna merah muda dan sepatu boots setinggi mata kaki. Host juga akan memakai aksesoris berupa bando berbentuk telinga kucing, choker berlonceng, dan sarung tangan berbentuk cakar kucing. Pemilihan warna bernuansa hitam dan merah muda untuk lebih menunjukkan warna kucing secara realitas, selain itu untuk menghindari objek menghilang karena pengambilan gambar host dilakukan di studio greenscreen dan akan ada perubahan background, sehingga warna hijau 
dilarang untuk digunakan. Penggunaan riasan juga terinspirasi oleh kucing, yaitu dengan penambahan gambar segitiga terbalik di bagian hidung dan garis horizontal sebagai kumis kucing. Penataan rambut akan diatur yaitu kuncir dua di samping sehingga menimbulkan kesan lucu dan manis.

Konsep editing ditata dengan mengutamakan kebutuhan gambar yang bervariasi dan penggunaan flat design. Penambahan info grafis bergaya flat design dengan menggunakan font yang tegas juga turut dihadirkan untuk menekankan informasi penting sehingga informasi tersebut dapat tersampaikan dengan baik kepada penonton. Warna-warna yang akan digunakan dalam program ini menggunakan warna-warna cerah seperti merah dan jingga untuk info grafis, merah muda untuk background program acara, dan merah dan peach untuk lower third. Grafis flat design akan ditempatkan pada lower third, framing pecahan shot, grid, informasi nama program acara dan info grafis. Penerapan konsep editing dibuat semenarik mungkin untuk menghindari kesan feature dan berita yang monoton dengan diwujudkan melalui teknik linier, penggunaan grid, split screen, dan transisi yang menarik.

\section{Pembahasan}

Proses pengambilan gambar program “Funtasy Zoo" dilakukan pada tanggal 10 -12 April 2019 untuk pengambilan gambar rubrik "Say, Hi!", "Hello, Doctor", dan "Let's
Play", 23 April 2019 untuk pengambilan gambar stockshot rubrik "Let's P lay", dan 25 April 2019 untuk pengambilan gambar vox pop dalam rubrik "Hello, Hooman". Program magazine sama halnya dengan program news dan dokumenter, yang membutuhkan kecekatan dalam menangkap momen tak terduga yang terjadi di lapangan pada saat proses liputan. Lokasi liputan yang memerlukan narasumber dilakukan di 2 lokasi, yaitu Rumah Sakit Hewan Prof. Soeparwi, Fakultas Kedokterran Hewan, Universitas Gadjah Mada, dan kafe Cats and Coffee di Jogjakarta. Selain itu, proses pengambilan gambar untuk stok gambar dilakukan di rumah rescuer kucing liar di Godean sedangkan untuk lokasi pengambilan vox pop dilakukan di jalan Malioboro.

Program magazine show "Funtasy Z0o" adalah program yang membahas seputar binatang dengan tema yang menyenangkan dan memainkan fantasi dalam penyajiannya. Program ini akan menyajikan informasi, berita, fakta menarik, tips, vox pop, lokasi menarik, dan videovideo lucu yang berkaitan dengan binatang yang bertarget penonton anak hingga remaja. Hadirnya program "Funtasy Zoo" diharapkan mampu menjadi program yang informatif, edukatif dengan tayangan yang disajikan dan inovatif karena program ini dikemas dengan format magazine show dan visual yang menarik dengan adanya host yang memakai kostum dan riasan binatang serta gaya visual 


\section{Bunga Nindiah Septiani, Agnes Widyasmoro, Andri Nur Patrio}

Memperkenalkan Dunia Binatang Melalui Penyutradaraan Program Magazine Show "F U NTASY ZO o"

flat design yang berwarna cerah. Tujuan program ini untuk memperkenalkan dunia binatang dengan cara yang menarik dan menyenangkan tanpa menghilangkan informasi penting kepada penonton. Tema pembahasan juga berdasarkan dari isu serta fenomena yang terkait dengan episode binatang yang akan dibahas, sehingga diharapkan program ini dapat membantu masyarakat mengenal binatang lebih dalam lagi.

Program magazine show "Funtasy Z00" merupakan acara berita ringan yang tidak terikat waktu dan berisi rubrik-rubrik tetap sebagai inti dari isi rubrik. Naratama mendefinisikan, "Magazine Show adalah format acara televisi yang mempunyai format menyerupai majalah (media cetak), yang di dalamnya terdiri dari berbagai macam rubrik dan tema yang disajikan dalam reportase aktual atau timeless sesuai dengan minat dan tendensi dari target penonton." (Naratama, 2004: 171).

\section{Program magazine show "Funtasy}

Zoo" berdurasi 30 menit yang terbagi menjadi 3 segmen dengan 7 rubrik didalamnya. Terdapat 3 rubrik yang memiliki aspek informatif yaitu rubrik "Say, Hi!", "Animazing!" , "Let's Play!" , kemudian ada 3 rubrik yang memiliki aspek edukatif yaitu rubrik "Do You Know?" "Hello, Doctor!" dan "Hello, Hooman!", dan satu rubrik "Ganimalery" yang memiliki aspek hiburan.

Pada segmen pertama, pembawa acara akan mengenalkan program karena episode kucing adalah episode satu dalam program " $F$ untasy Zoo".

Setelah opening, masuk ke rubrik "Say, Hi!" yang membahas tentang karakteristik kucing, kemudian disusul dengan rubrik "Animazing!", berisikan 3 berita kucing hebat yang datanya didapatkan dari media youtube dan instagram, dan rubrik terakhir di segmen pertama adalah " Do you know?" berisi fakta alasan kucing bersinar di malam hari dan fungsi kumis kucing yang disajikan dalam bentuk animasi.

Pada segmen kedua, terdapat 2 rubrik, yaitu rubrik "Hello, Doctor!" dan rubrik "Hello, Hooman". Rubrik "H ello, D octor!" berupa tayangan liputan bersama dokter hewan yang menjelaskan pencegahan kucing terkena diare, kemudian rubrik "Hello, Hooman" berisi tayangan voxpop mengenai alasan kucing makan rumput dan alasan kucing suka mengejar laser seperti mengejar buruannya, dan pertanyaan tersebut akan dijelaskan oleh dokter hewan. Pada segmen ketiga, terdapat 2 rubrik yaitu rubrik "Let's Play!" dan rubrik "Ganimalery" . Pembawa acara kembali menyapa dan mengantarkan masuk ke rubrik "Let's Play" yang berisi liputan kafe Cats and Coffee di Yogyakarta, disusul dengan rubrik terakhir yaitu "Ganimalery" berisi 2 video lucu dan jahil kucing yang disebarkan di media youtube dan instagram. Pembawa acara akan menutup acara dengan membacakan kesimpulan dan 
bumper program hadir sebagai penutup program "F untasy Zoo".

Program "Funtasy Zoo" menghadirkan 7 rubrik tetap yang bertujuan untuk meyampaikan informasi ringan kepada penonton dengan pembawaan yang ringan dan menghibur. Nama rubrik-rubrik tersebut merupakan inti dari isi rubrik sehingga materi yang disampaikan juga disesuiakan dengan rubrik yang telah ada. Sebagai pembeda antara program berita dengan magazine show, program "Funtasy Zoo" lebih mengangkat berita ringan dan menghibur daripada berita kuat. Hal ini dikuatkan dengan pernyataan Anton Mabruri yang menuliskan (Anton M. 2018: 184), perbedaan itu ialah:

1. Jika materi berita yang disajikan lebih banyak berita kuat, sedangkan feature-nya lebih sedikit, mata acara ini disebut siaran berita (news gathering).

2. Jika materi berita yang disajikan lebih banyak feature, sedangkan berita kuatnya hanya sedikit, mata acara ini disebut majalah udara (magazine show).

Penataan kamera pada program "Funtasy Zoo" untuk lokasi di studio menggunakan multi camera sedangkan untuk liputan disesuaikan dengan lokasi. Pengambilan gambar di studio dengan multi camera menggunakan frame size full shot yang terletak di depan pembawa acara sebagai kamera master, kemudian untuk kamera dua menggunakan frame size medium shot yang terletak di sisi kiri pembawa acara lalu dilakukan lagi pengambilan gambar untuk frame size medium shot dari arah depan. Pemilihan frame size dan posisi kamera ini terinspirasi oleh program "I Look" NET TV yang dipilih sebagai tinjauan karya dalam program "F untasy Zoo".

Pemilihan komposisi pada pembawa acara yaitu rule of third, komposisi ini dipilih karena pada sisi kosong akan diberi info grafis sebagai penekanan infomasi kepada penonton. Selain itu frame size yang dipilih pada pengambilan gambar pembawa acara yaitu full shot dan medium shot. Frame size tersebut dipilih karena full shot akan memperliatkan visual pembawa acara secara menyeluruh, mulai dari kepala hingga kaki, selain itu untuk memperlihatkan gerakan pembawa acara secara menyeluruh. Shot size medium shot dipilih karena untuk memperlihatkan ekspresi, pembawa acara, memberikan kesan dekat, dan persuasif kepada penonton.

Pengambilan gambar liputan disesuaikan dengan lokasi, seperti halnya pada pengambilan gambar wawancara yang dilakukan dengan multi camera dengan frame size medium shot dan medium close up. Hal ini bertujuan untuk menambah variasi shot sehingga tidak terasa membosankan, dan penonton merasa dekat dengan narasumber karena dapat meliht ekspresi narasumber dengan jelas. Pengambilan gambar secara detail juga dilakukan untuk menambah stok 


\section{Bunga Nindiah Septiani, Agnes Widyasmoro, Andri Nur Patrio}

Memperkenalkan Dunia Binatang Melalui Penyutradaraan Program Magazine Show "FUNTASY ZO0"

gambar agar visual yang ditayangkan lebih bervariatif dan menarik.

Program "Funtasy Zoo"
menggunakan mic clip on dan mic dynamic handheld pada pengambilan gambar host dan liputan. Pengambilan suara voice over (VO) untuk kebutuhan narasi, dilakukan di studio rekaman suara milik Jurusan Televisi, Fakultas Seni Media Rekam, ISI Yogyakarta pada 29 Maret 2019. Narasi ini dijadikan acuan untuk proses pengambilan gambar, pengumpulan data, dan proses edit. Untuk musik latar belakang menggunakan aransemen musik dengan nada, tempo, dan ritme yang ceria dan lucu. Music jingle untuk bumper program, menggunakan aransemen bertempo ceria dan dengan aransemen lebih meriah agar lebih menarik penonton secara audio. Selain itu musik pada setiap rubrik juga disesuaikan dengan pembahasan rubrik, yaitu rubrik "Say,Hi!" memiliki musik dengan tempo cepat dan bernuansa jahil dan nakal untuk rubrik "Ganimalery" yang berupa rubrik video-video lucu binatang.

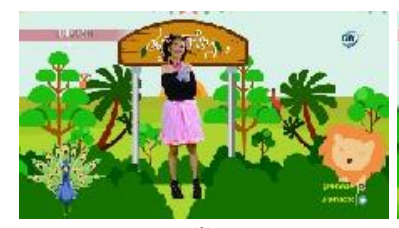

(i)

Gambar 2.(i-ii). Frame size host

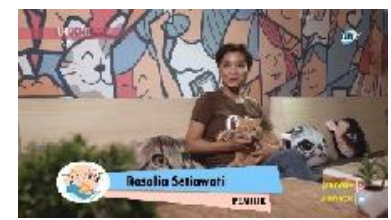

(i)

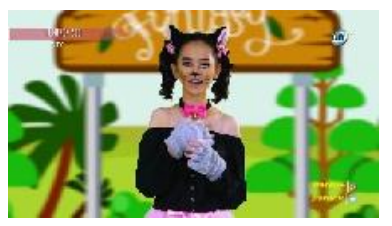

(ii)

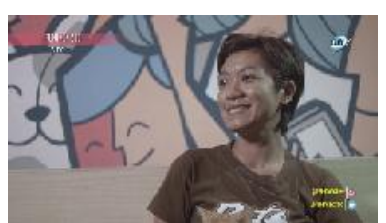

(ii)
Gambar 3. (i-ii). Frame size wawancara
Program "F untasy

Zoo"

menggunakan penataan setting studio green screen untuk pengambilan gambar pembawa acara. Pada pengambilan gambar ini, tidak diperlukan properti, pembawa acara hanya berdiri dalam membawakan acara dengan mengandalkan ekspresi, gesture, serta gerakan yang hanya maju, mundur dan bergeser ke samping kanan dan kiri. Hal ini terinspirasi oleh program "iLook" di NET TV yang juga menggunakan setting studio green screen untuk pengambilan gambar pembawa acaranya. Program ini menggunakan tatanan rias dan busana yang terinspirasi oleh cosplay kucing, mengingat episode yang disampaikan adalah binatang kucing. Pemilihan warna kostum ditentukan dengan menghindari warna hijau mengingat lokasi pengambilna gambar berada di studio greenscreen dan akan diganti latarnya dengan desain kebun binatang bergaya flat design pada proses edit online.

Program "Funtasy Zoo" merupakan program magazine yang terbagi dalam 3 segmen berdurasi 30 menit. Ketepatan gambar dan narasi yang diucapkan diatur dalam edit offline sehingga menciptakan tayangan yang serasi agar informasi yang ingin disalurkan dapat tersampaikan dengan baik kepada penonton. Data ketujuh rubrik itu disatukan dengan pembagian porsi yang tepat dengan sesi pengantar dari pembawa acara. Program "Funtasy Zoo" merupakan program yang menghadirkan banyak rubrik, 
diantaranya adalah rubrik yang menggunakan pengambilan gambar liputan. Liputan yang dilakukan tidak hanya di luar ruangan (outdoor), tetapi juga di dalam ruangan (indoor). Pada pengambilan gambar ini mempengaruhi keadaan cahaya yang berbeda pula, sehingga dibutuhkan pengoreksian warna pada proses edit online agar tampilan terlihat sama dan tidak ada jumping cahaya antar potongannya. Pada proses ini juga dimasukkan elemen-elemen pendukung lain seperti grafis dan pergantian background green screen pada sesi pembawa acara.

Program "Funtasy Zoo" menggunakan bumper dengan desain kumpulan binatang yang mewakili jenisnya berdasarkan tempat tinggal, seperti burung macaw yang mewakili hewan darat, singa yang mewakili hewan darat buas, ikan paus yang mewakili hewan laut, dan kucing yang mewakili hewan darat peliharaan. Binatang yang dihadirkan dalam bentuk ilustrasi dipilih dengan desain yang sederhana, menyederhanakan bentuk aslinya, datar, namun terkesan lucu dengan adanya ekspresi senyum di wajah binatangnya. Penataan letak juga diatur dengan memfokuskan binatangbinatang tersebut hanya berada di tengah layar dengan gerakan yang sederhana sehingga tidak menghilangkan identitas gaya grafis flat design. Tipografi yang dipilih juga berdasarkan tema program, yaitu fantasi, keceriaan, sehingga font Aldine dipilih karena termasuk dalam jenis font miscellaneous. Menurut James Craig (2007), font ini merupakan pengembangan dari bentuk-bentuk yang sudah ada, ditambah hiasan dan ornamen, atau garis-garis dekoratif, sehingga memiliki kesan dekoratif dan ornamental. (DumetSchool, 2014)

$$
\text { Program "Funtasy Zoo" }
$$

menggunakan bumper rubrik dengan desain binatang yang mewakili setiap rubrik, seperti kucing yang mewakili rubrik perkenalan "Say, Hi!", kucing dipilih sebagai ikon binatang yang akan dibahas dalam tayangan episode program "Funtasy Zoo". Burung merak yang mewakili rubrik berita mengagumkan "Animazing!" , burung merak dipilih karena burung ini dipercaya sebagai burung yang mengagumkan karena ekornya yang indah saat terbuka, sehingga cocok untuk rubrik "Animazing" yang menghadirkan berita-berita mengagumkan. Burung hantu yang mewakili rubrik fakta menarik "Do you know?", ikan koi yang mewakili rubrik kesehatan hewan "Hello, Doctor!", burung nuri yang mewakili rubrik tanya jawab masyarakat "Hello, Hooman", anjing yang mewakili rubrik lokasi unik “Let's Play!” dan harimau yang mewakili rubrik video-video lucu "Ganimalery". Tiap bumper rubrik memiliki warna latar belakang berbeda-beda yang disesuaikan dengan arti warna menurut psikologi. 


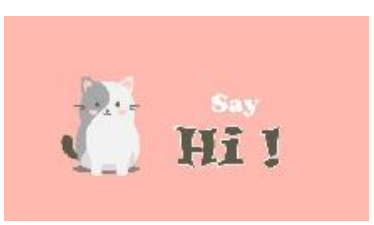

(i)

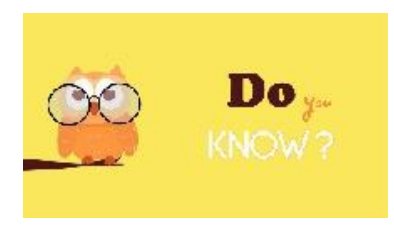

(iii)

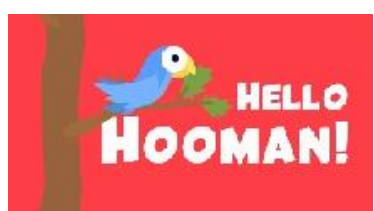

(v)

(vi)

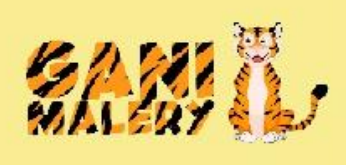

(vii)

Gambar 3. (i-vii). Bumper 7 rubrik

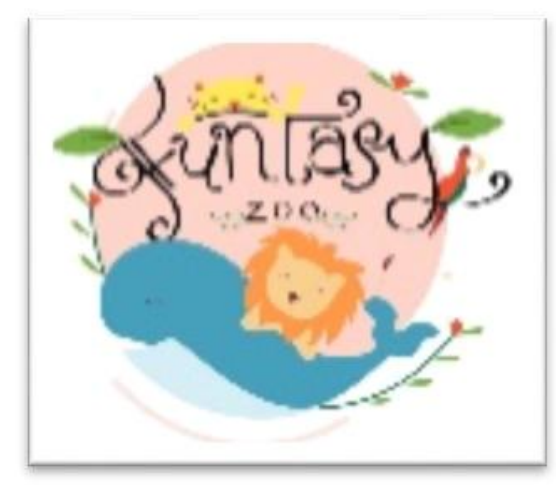

Gambar 4. Bumper program "Funtasy Zoo"

\section{Kesimpulan}

Program "Funtasy Zoo" adalah program magazine show yang membahas seputar binatang dengan tema yang menyenangkan dan memainkan fantasi dalam penyajiannya, sehingga diharapkan dapat memberikan pengetahuan tentang binatang namun tetap menghibur. Hadirnya program "Funtasy Zoo" diharapkan mampu menjadi program yang informatif, edukatif dengan tayangan yang disajikan dan inovatif karena program ini dikemas dengan format magazine show dan visual yang menarik dengan adanya host yang memakai kostum dan riasan binatang serta gaya visual flat design yang berwarna cerah. Aspek informatif tersebut dirangkum dalam rubrik "Say, Hi!", "Animazing!", dan "Let's Play!" serta hal yang bersifat edukasi dirangkum dalam rubrik "Do You Know?", "Hello, Doctor!" dan "Hello, Hooman", sedangkan hal bersifat menghibur terdapat pada rubrik "Ganimalery". Program "Funtasy Zoo" dikemas dengan format magazine show sehingga menjadi tayangan yang inovatif mengingat sedikitnya program tentang dunia binatang berformat magazine show serta tampilan visual yang bergaya flat design untuk desain program bertema binatang, karena pada umumnya gaya flat design ditujukan untuk program yang bersifat formal seperti softnews, seperti program “iLook" dan "WonderFood” NET TV.

Program magazine show "Funtasy

Zoo" dipandu oleh seorang remaja wanita yang ceria dan enerjik. Penyajian informasi didapatkan melalui liputan di lokasi berupa wawancara dengan narasumber, video-video yang didapatkan dari media sosial youtube, video animasi 2D, dan voice over (VO) bernada lucu juga hadir sebagai pendukung informasi. Penyajian gambar dengan variasi shot, angle, dan komposisi yang dinamis 
mendukung visual sehingga menambah daya tarik program dan menghindari kejenuhan pada mata penonton. Backsound yang enerjik, ceria, dan menyenangkan juga dihadirkan untuk menambah suasana ceria dan menjadi salah satu daya tarik penonton.

$$
\text { Program magazine show "Funtasy }
$$

Zoo" bernuansa grafis flat design.

Penggunaan warna-warna cerah dan solid seperti warna merah muda dan biru langit, ilustrasi sederhana tanpa dimensi, dan warna solid yang cerah menjadi ciri khas program, karena mengingat segmentasi penonton adalah anak-anak dan remaja. Penggunaan grafis flat design ditempatkan pada background host, bumper, split screen, lower third, info grafis, teks pertanyaan, animasi 2 dimensi, dan credit tittle.

\section{Daftar Pustaka}

Amir Piliang, Yasraf. Hipersemiotika. Yogyakarta: Jalasutra, 2013.

Artha, Dian. Ensiklopedia Tubuh Manusia, Binatang, dan Tumbuhan: Pertanyaan dan Jawaban. Jakarta: CV Dian Artha, 2007.

Azhar, Mohd. Panduan Meningkatkan Kecerdasan Emosi.Jakarta: PTS Profesional, 2004.

Dameria, A. Color Basic Panduan Dasar untuk Desainer \& Industri Grafika. Jakarta: Link \& Match Graphic, 2007.

Ensiklopedia Nasional Indonesia. Jakarta: PT. Delta Pamungkas, 1997.

Fitriani, Aswitaratih, terj. Illustrated Encyclopedia of Animals. London: Dorling Kendersley Limited, 2008.

Gumelar, M.S. Memproduksi Animasi TV: Solusi Murah \& Cepat. Jakarta: PT Gramedia, 2002.
Heizer, Jay dan Barry Render. Manajemen Operasi Buku 1 Edisi 9. Jakarta: Salemba 4, 2009.

Kleden, Ignas. Sikap Ilmiah dan Kritik Kebudayaan. Jakarta: LP3ES, 1987.

Kusrianto, Adi. Pengantar Desain Komunikasi Visual. Yogyakarta: Andi Offset, 2007.

Latief, Rusman, danYusiatie Utud. Kreatif Siaran Televisi: Hard News, Soft News, Drama, Non-Drama. Jakarta: KencanaPrenadamedia Group, 2017.

Mabruri KN, Anton. Manajemen Produksi Program TV, Format Acara NonDrama,News \& Sport. Jakarta: Grasindo, 2013.

Manis, Hoeda. Ensiklopedi Dunia Dalam Binatang: Fakta-fakta Unik dan Menarik Dunia Hewan. Yogyakarta: Ar-Ruzz Media, 2014.

Mascelli, A.S.C. Joseph (terjemahan H. M. Y Biran). 1987. Angle-Kontiniti-EditingClose Up-Komposisi dalam Sinematografi. Jakarta: Yayasan Citra.

McLuhan, Marshall. The Medium is The Message. UK: Penguin Books, 1967.

Morrisan, Andy Corry Wardhani, dan Farid Hamid. Teori Komunikasi Massa: Media, Budaya, dan Masyarakat. Bogor: Ghalia Indonesia, 2013.

Morrisan. Jurnalistik Televisi Mutakhir. Jakarta: Kencana Prenada Media Group, 2005.

Murti, Krisna. Video Public. Yogyakarta: Kanisius, 1999.

Morrisan. Manajemen Media Penyiaran, Strategi Mengelola Radio dan Televisi. Jakarta: Kencana Prenada Media Group, 2009.

Parsuki, Drs. Buku Diklat Dasar-Dasar Animasi. Program Studi DKV jurusan Desain FRSD ISI Yogyakarta, 1987.

Pujiriyanto. Desain Grafis Komputer: Teori grafis komputer. Yogyakarta: Penerbit Andi, 2005.

Rukmananda, Naratama. Menjadi Sutradara Televisi: dengan Single dan Multi Camera. Jakarta: PT Grasindo, 2006.

Sachari, Agus. Budaya Visual Indonesia. Bandung: Erlangga, 2001. 
Sanyoto, Sadjiman E. Nirmana: Elemenelemen Seni dan Desain. Yogyakarta: Jalasutra, 2009.

Set, Sony. Menjadi Perancang Program Televise Profesional. Yogyakarta: Penerbit Andi, 2008.

Soedarso. Sejarah Perkembangan Seni Rupa Modern. Yogyakarta: ISI Yogyakarta, 1986.

Sparke, Penny. A Century of Design: Design Pioners of 20th Century. London: Mitchell Beazley, 1998.

Turangan, Lily, Willyanto, dan Reza Fadhilla. Seni Budaya \& Warisan Indonesia: volume 4, Fauna. Jakarta: PT AkuBisa, 2014

Wibowo, Fred. Dasar-Dasar Produksi Program Televisi. Jakarta: Gramedia

\section{Daftar Laman}

CatLovers.

https://www.catlovers.id/ternyata-ini-alasankucing-peliharaan-makan-rumput/ (diakses pada 01 Oktober 2018 pukul 18.59 WIB)

Gudegnet.

https://gudeg.net/direktori/7637/cats-andcoffee-jogja.html (diakses pada 12 Oktober 2019)

HarianMetro.

https://www.hmetro.com.my/node/100514 (diakses pada 11 Juni 2019 pukul 18.47 WIB)

International Design School.

https://idseducation.com/articles/seputarflat-design-yang-perlu-kamu-tahu/ (diakses pada 11 Juni 2019 pukul 20.16 WIB)

KBBI. http://www.kbbi.kemdikbud.go.id/entri/ (diakses pada 11 Juni 2019 pukul 19.05 WIB)

Klikdokter.

https://www.klikdokter.com/infosehat/read/3280728/hilangkan-stressdengan-melihat-ikan-berenang-diakuarium (diakses pada 11 Juli 2019 pukul 08.21 WIB)

KompasInternasional.

https://internasional.kompas.com/read/2013/ 01/02/20160666/Kisah.Anjing.Buta.da n.Kucing.Penuntunnya/ (diakses pada 30 September 2018 pukul 22.25 WIB) Majalah Bobo.

https://bobo.grid.id/read/081599052/kenapakucing-suka-mengejar-sinar-laserseperti-mengejar-mangsa?page $=$ all (diakses pada 14 Junii 2019 pukul 14.52 WIB)

Mania Kucing.

https://maniakucing.com/kucingragdolls/\#top (diakses pada 14 Oktober 2018 pukul $10.56 \mathrm{WIB}$ )

Meowmagz.

https://meowmagz.com/2016/04/mengapakucing-aktif-saat-malam-hari/ (diakses pada 30 Januari 2019 pukul 11.51 WIB)

NET Media.

http://netmedia.co.id/program/513/ (diakses pada 12 Oktober 2018 pukul 15.34 WIB)

Undang-Undang No.5 Tentang Konservasi Sumber Daya Alam Hayati dan Ekosistemnya.

https://pih.kemlu.go.id/files/UU\%20RI\%20 NO\%2005\%20TAHUN\%201990.pdf (diakses pada 12 Oktober 2018 pukul 19.15 WIB) 